\title{
Exercise Dependence in Amateur Competitors and Non-Competitor Recreational Exercisers
}

\author{
Zsuzsa Menczel ${ }^{1} \cdot$ Mark D. Griffiths $^{2}$ • \\ István Vingender ${ }^{1}$ - Andrea Eisinger ${ }^{3,4}$. \\ Judit Farkas $^{3,5}$ - Anna Magi ${ }^{3,4}$ • Barbara Mervó ${ }^{3,4}$. \\ Gyöngyi Kökönyei $^{3} \cdot$ Zsolt Demetrovics $^{3}$
}

(C) Springer Science+Business Media New York 2016

\begin{abstract}
Research has demonstrated that exercising has health promoting effects. However, if habitual sporting activities become uncontrollable, detrimental health consequences can occur among a minority of individuals. Furthermore, such obligatory exercise can cause serious decline in school/work productivity, as well as financial problems, relationship problems, and poor psychological and physical wellbeing. The aim of the present study was to compare characteristics related to exercise dependence (ED) between recreational exercisers and amateur competitors. A total of 1439 participants (41.4 \% male; mean age $=32$ years) completed a battery of measures including the Exercise Dependence Scale (EDS), SCOFF, Well-Being Questionnaire, and Rosenberg's Self-Esteem Scale. Results showed that $6.5 \%$ of participants identified themselves as amateur competitive exercisers. Amateur competitors exercised significantly more $(6.4 \mathrm{~h})$ than non-competitor recreational exercisers $(4.6 \mathrm{~h})$. Amateur competitors also scored significantly higher on the EDS. Significant effects were found between competing and self-esteem concerning ED. Results showed that both features had a strong effect on ED. The study highlights the connection between ED symptoms and lower self-esteem and/or lower levels of subjective wellbeing. These influential factors are worth considering when planning preventive interventions addressing ED for both amateur competitors and non-competitive recreational athletes as well as when promoting sport as a healthy activity.
\end{abstract}

Zsolt Demetrovics

demetrovics@t-online.hu

1 Faculty of Health Sciences, Semmelweis University, Budapest, Hungary

2 Nottingham Trent University, Nottingham, UK

3 Institute of Psychology, Eötvös Loránd University, Budapest, Hungary

4 Doctoral School of Psychology, Eötvös Loránd University, Budapest, Hungary

5 Nyírő Gyula Hospital, Budapest, Hungary 
Keywords Exercise addiction - Amateur competitors - Non-competitive recreational athletes .

Self-esteem

Empirical research has demonstrated the benefits of sport and exercise in relation to mental and physical health (Warburton et al. 2006). There is no doubt that regular exercise has health promoting effects and helps prevent endemic clinical conditions such as cardiovascular disease, diabetes, and cancer. The preventive effects of exercise can be detected in specific mental illnesses (such as depression, anxiety, mood modification (Gémes 2006) and has also been shown to improve self-esteem and self-confidence. However, if habitual exercise starts to become uncontrollable (such as increasing amounts of excessive workouts or exercise more generally) negative health consequences can begin to occur. Research has also demonstrated that obligatory exercise can cause serious decline in school/work capacity, as well as financial problems, relationship problems, and poor psychological and physical wellbeing (Hausenblas and Symons Downs 2002a).

Exercise dependence (ED) is defined as high commitment to leisure time exercising, while causing troubles physically and/or psychologically (Hausenblas and Symons Downs 2002a). It has been described as a behavioral addiction (Berczik et al. 2012), although unlike Gambling Disorder and Internet Gaming Disorder it is not yet listed as a separate disorder in DSM-5 (Griffiths 1997). Research into ED began about 40 years ago and these early studies were characterized by highly varying prevalence rates (Hausenblas and Symons Downs 2002a). This high variance in prevalence rate is most likely due to (i) the numerous different instruments used to assess the phenomenon, and (ii) the great variability in size and sociodemographic make-up of the populations investigated. Initially, ED was assessed in college and university students with the results ranging from 1 to $3 \%$ (Hausenblas and Symons Downs 2002b; Terry et al. 2004). To the authors' knowledge, only one study has ever been carried out using a nationally representative sample. More specifically, Mónok et al. (2012) reported that $0.3-0.5 \%$ of the Hungarian population were at risk for ED. However, the same study also reported that $6.2-10.1 \%$ had ED symptoms.

Other recent studies surveying smaller and more specific samples have reported different prevalence rates of ED. In a study of 203 amateur triathlon race participants (Blaydon and Lindner 2002), Blaydon reported that triathletes showed particularly high levels of ED symptoms with $50 \%$ of participants being classed as exercise dependent. Another study with 1285 triathletes by Youngman (2007) found lower rates of compulsive exercising (20\%), although $79 \%$ of the participants showed at least one symptom. In a small study of 95 French ultra-marathoners, Allegre et al. (2007) reported that only three participants (3.2\%) were at risk of ED. Szabo et al. (2013) compared ultra-marathoners $(n=95)$ with two Spanish groups of university athletes (57 sport students and 90 non-sport students). They reported that $17 \%$ of ultra-marathoners were at risk of ED compared to 7-10\% in university athletes. Lichtenstein et al. $(2014 \mathrm{a}, \mathrm{b})$ surveyed 588 fitness exercisers and football players and reported $5.8 \%$ at risk of ED. Another follow-up study led Lichtenstein et al. (2014a) found that young male footballers were $7.1 \%$ at risk of ED with general fitness participants at $9.7 \%$ risk.

Modolo et al. (2011) studied 300 amateur athletes and reported 33.2\% were at risk of ED. Similar studies in recreational exercisers have yielded wide ED prevalence rates. In Parisian fitness centers in France, Lejoyeux et al. (2008) found that $42 \%$ of 300 customers had problems related to ED, while studies investigating 423 Sicilian and Calabrian gym visitors, Costa and Oliva (2012) reported only $7 \%$ to be at risk of ED. Szabo and Griffiths (2007) surveyed 451 
exercisers and reported that $6.9 \%$ of British sport-science students $(n=261)$ were at risk of ED compared to $3.6 \%$ of British gym users $(n=194)$. Warner and Griffiths (2006) found similar results and reported that $8 \%$ of British gym users $(n=100)$ were dependent on exercise.

As noted above, these studies highlight the prevalence rates of ED vary greatly. While in the normal population it remains under $1 \%$ and in college and university students it ranges from 1 to $6 \%$ (depending upon the course being studied), amateur exercisers might be at a much higher risk of ED. Recreational exercisers show 2-10\% prevalence and in amateur athletes regularly attending competitions the prevalence can be as high as 20-52\% (Hausenblas and Symons Downs 2002b; Terry et al. 2004; Blaydon and Lindner 2002; Youngman 2007).

The aim of the present study was to examine which characteristics related to exercise dependence differ in recreational exercisers compared to amateur competitive exercisers. It was hypothesized that amateur competitive exercisers would show more signs of exercise dependence and have a higher self-reported quality of life than recreational exercisers not participating in competitions. It was also hypothesized that recreational exercisers would have lower levels of self-esteem than amateur competitive exercisers.

\section{Methods}

\section{Participants and Procedure}

Data were collected in 17 fitness centers in Budapest. In all cases, managers were asked if data collection could begin immediately. Participation in the research was voluntary and anonymous. For data collection, potential participants were asked on their way home if they would take part in the research study. If they agreed to participate, they provided a personal email address. Within $24 \mathrm{~h}$ of agreeing to participate, individuals received an email, that contained a password to the online survey.

\section{Measures}

Socio-Demographic Questions In this part of the survey, participants were asked about their gender, age, marital status, residence, education, and financial income.

Exercising Activity Participants were asked about their exercise and sporting habits, including their weekly amount of exercising, what sports and types of exercise they engaged in, and if they regularly participated in sporting competitions or not.

Anthropometric Data From weight and height data, each participant's Body Mass Index (BMI) was calculated.

Exercise Dependence (Exercise Dependence Scale [EDS]) The EDS was developed by Hausenblas and Symons Downs (2002c) in order to assess obligatory exercise. The scale was adapted to Hungarian by Demetrovics and Kurimay (Berczik et al. 2012). EDS criteria were derived from DSM-IV substance addiction criteria (Hausenblas and Symons Downs 2002c). The scale comprises 7 subscales, with three statements belonging to each subscale. All 21 items are rated on a 6-point Likert scale. The internal consistency of the test was excellent (Cronbach's $\alpha=0.90$ ). 
Eating Disorders To differentiate whether any participants had a primary or secondary ED, it needs to be determined whether individuals also have an eating disorder. Consequently, all participants were asked to complete the SCOFF questionnaire. The SCOFF comprises five questions and is a quick and easy tool to screen for eating disorders. The instrument was developed by Morgan et al. (1999) and all items are yes/no questions. Two or more positive responses indicate an eating disorder. However, the SCOFF is not a clinical diagnostic tool. It may indicate an eating disorder but further diagnosis is needed. In the present study, the internal reliability of the SCOFF was relatively low (Cronbach's $\alpha=0.48$ ).

WHO Well-Being Questionnaire (WBI) The WBI was developed to assess an individual's own feelings about their health and their positive quality of life (Susánszky et al. 2006). Using a four-point Likert scale the maximum score is 15 . Higher scores indicate a higher level of positive feelings regarding one's own health belief. The reliability of the scale was satisfactory and Cronbach's $\alpha=0.78$.

Rosenberg's Self-Esteem Scale (RSES) The RSES contains Rosenberg's ten items concerning general self-esteem, and refer to individuals' positive or negative attitude towards themselves (Rosenberg 1965). In the ten items, five positive and five reverse questions are responded to on a four-point Likert scale. The higher the score on the RSES, the higher the level of self-esteem. The maximum score on the RSES is 30. The internal reliability of the scale was satisfactory (Cronbach's $\alpha=0.86$ ).

Ethics The study procedures were carried out in accordance with the Declaration of Helsinki. The Institutional Review Board of the research team's University approved the study. All participants were informed and debriefed about the study and all provided informed consent to participate.

\section{Results}

\section{Descriptive Statistics}

The sample included data from 1743 regular exercisers. A total of 302 participants who appeared to have an eating disorder according to the SCOFF test were excluded from subsequent analysis. Of the 1439 remaining participants, $6.5 \%$ identified themselves as amateur competitive exercisers $(n=93)$. The sample comprised $41.4 \%$ males, and the age range was between 18 and 61 years (mean age $=32$ years; $\mathrm{SD}=8.44$ ). In relation to marital status, more than half of the sample's participants were in a relationship $(62.5 \%)$ while $37.5 \%$ were single. Most participants $(84.7 \%$ ) lived in Budapest. The educational qualifications of the sample showed that $31.8 \%$ finished high school and that two-thirds $(65.4 \%)$ also had a college/university degree. The average BMI of the sample fell in the normal range $(\mathrm{M}=23.8$; $\mathrm{SD}=3.83$ ). In relation to the weekly amount of exercising, the average number of exercising sessions was $2.8(\mathrm{SD}=1.4)$ and participants spent an average of $4.1 \mathrm{~h}(\mathrm{SD}=3.5)$ exercising per week. Information concerning socio-demographic variables is presented in Table 1.

Recreational exercisers had significantly fewer exercise sessions (2.7 times per week) than amateur competitive exercisers (3.5 times per week) $(t=5.48, p \leq 0.001)$. Furthermore, amateur competitive exercisers spent significantly more time exercising $(6.4 \mathrm{~h})$ than regular 
Table 1 Main characteristics of the sample

\begin{tabular}{|c|c|c|c|c|c|c|}
\hline \multirow[t]{2}{*}{ Descriptives } & \multicolumn{3}{|c|}{$\begin{array}{l}\text { Amateur competitive exercisers } \\
N=93\end{array}$} & \multicolumn{3}{|c|}{$\begin{array}{l}\text { Recreational exercisers } \\
N=1346\end{array}$} \\
\hline & Frequency $(\%)$ & Mean & SD & Frequency $(\%)$ & Mean & SD \\
\hline Age & & 29.35 & 8.65 & & 32.18 & 8.39 \\
\hline \multicolumn{7}{|l|}{ Gender } \\
\hline Male & 73.1 & & & 43.3 & & \\
\hline Female & 26.9 & & & 56.7 & & \\
\hline \multicolumn{7}{|l|}{ Marital status } \\
\hline Single & 41.9 & & & 31.4 & & \\
\hline In a relationship & 41.9 & & & 38.0 & & \\
\hline Married & 11.8 & & & 25.0 & & \\
\hline Divorced & 4.3 & & & 5.2 & & \\
\hline Widow & - & & & 0.3 & & \\
\hline \multicolumn{7}{|l|}{ Residency } \\
\hline Capital & 75.0 & & & 85.4 & & \\
\hline Country & 7.6 & & & 2.8 & & \\
\hline Other city & 12.0 & & & 8.9 & & \\
\hline Village & 5.4 & & & 2.8 & & \\
\hline \multicolumn{7}{|l|}{ Education } \\
\hline Elementary & 4.3 & & & 1.1 & & \\
\hline Less than HS & 3.2 & & & 1.2 & & \\
\hline HS Graduate & 43.0 & & & 31.2 & & \\
\hline College/University & 49.5 & & & 66.5 & & \\
\hline
\end{tabular}

HS High School

exercisers $(4.6 \mathrm{~h})(t=7.03, p \leq 0.001)$. In relation to age, amateur competitive exercisers were (on average) 2.8 years younger than recreational exercisers $(t=3.13, p=0.002)$.

Based on EDS scores, 32 participants $(2.2 \%)$ were classified as at-risk, while 991 participants $(69.3 \%)$ were classified as nondependent-symptomatic. There were significant differences between amateur competitive exercisers and recreational exercisers classified as atrisk for $\mathrm{ED}(t=6.248, p \leq 0.001)$. Amateur competitive exercisers scored significantly higher on $\operatorname{EDS}\left(\mathrm{M}_{\mathrm{ACE}}=62.1, \mathrm{SD}=15.14 ; \mathrm{MRE}=51.9 \mathrm{SD}=15.27\right)$. The prevalance rates of exercise dependence, BMI, and exercise frequency are shown in Table 2.

In relation to subjective wellbeing in amateur competitive exercisers, a weak reverse correlation was found with $\mathrm{ED}(r=-0.204, p=0.049)$. In recreational exercisers, no association was found between wellbeing and $\operatorname{ED}(r=0.026, p=0.344)$. There was a significant association between self-esteem and ED scores $(\mathrm{F}=13.211, p \leq 0.001)$. Post-hoc analysis revealed that participants without any ED symptoms had higher self-esteem than participants in the symptomatic group. Univariate analysis of variance revealed significant effects between competing and self-esteem concerning $\mathrm{ED}\left(\mathrm{F}_{\mathrm{RSES}}=17,984, p \leq 0001\right.$; $\left.\mathrm{F}_{\mathrm{ACE}}=40,946, p \leq 0001\right)$. Results show that both features have a strong effect on ED. Further analysis showed that taking part in a competition has a stronger influence on $\mathrm{ED}$ than recreational exercising without competing $\left(\mathrm{M}_{\mathrm{ACE}}=62.1, \mathrm{SD}=1.567\right.$ $\mathrm{MRE}=51.9, \mathrm{SD}=15.27$ ). 
Table 2 The prevalence of exercise dependence, BMI and exercise frequency

\begin{tabular}{lllll}
\hline & & $\begin{array}{l}\text { Regular } \\
\text { exercisers }\end{array}$ & $\begin{array}{l}\text { Amateur competitive } \\
\text { exercisers }\end{array}$ & Total \\
\hline ED - at-risk & $\mathrm{N}$ & 30 & 2 & 32 \\
& $\%$ & 2.3 & 2.2 & 2.2 \\
ED - symptomatic & $\mathrm{N}$ & 910 & 80 & 991 \\
& $\%$ & 68.4 & 86 & 68.9 \\
ED- asymptomatic & $\mathrm{N}$ & 391 & 11 & 408 \\
Body mass index & $\%$ & 29.4 & 11.8 & 28.5 \\
& $\mathrm{M}$ & 23.63 & 23.41 & 23.63 \\
Exercise frequency- weekly & $\mathrm{SD}$ & 3.67 & 2.99 & 3.63 \\
& $\mathrm{M}$ & 2.65 & 3.54 & 2.71 \\
Exercise frequency - hourly & $\mathrm{SD}$ & 1.35 & 1.52 & 1.38 \\
& $\mathrm{M}$ & 4.60 & 6.42 & 4.72 \\
& $\mathrm{SD}$ & 2.16 & 2.43 & 2.23 \\
\hline
\end{tabular}

\section{Discussion}

In the present study exercise dependence (ED) was examined from a new perspective. Research into excessive exercise dates back over four decades. However, there has been a marked increase of interest towards this issue during the past few years as shown in a recent bibliometric analysis of papers in the area by Szabo and colleagues (Szabo et al. 2015). Although several groups of exerciser have been examined in previous studies (ultra-marathoners, triathletes, gym club members, sports science students, university athletes, footballers, etc.) have already, the present authors are unaware of any survey studies specifically examining amateur athletes regularly participating in competitions (although there is a case study of a female exercise addict who got into severe financial trouble partly due to the number of competitive events that she registered to participate in and the traveling costs associated with competing all over the UK [Griffiths 1997]). For this reason, our study was focusing on possible differences and similarities between amateur competitive exercisers and regular recreational exercisers with respect to ED.

A minority of the total sample (6.5\%) regarded themselves as amateur competitive exercisers, while the majority of participants $(93.5 \%)$ were classed as regular recreational exercisers (thus forming the control group). Results showed that the amateur competitive exercisers were younger and they exercised more than recreational exercisers in terms of both number of sessions a week and total time expenditure. There was no significant difference between the two groups' BMI, and both groups fell in the normal range. This finding provides evidence that ED and eating disorders are separate disorders. Only $2 \%$ of the total sample belonged to the group considered at risk concerning ED. This rate is lower than that found in many other studies (Modolo et al. 2011; Lejoyeux et al. 2008).

However, it is arguably more important to highlight the high rate of individuals in the sample reporting at least some of the ED symptoms (i.e., $70 \%$ ). This finding suggests that the majority of respondents had some problematic symptoms relating to exercise even if there was no overall problem. This suggests attention should be paid to those individuals with a preventive approach in mind. Further research is needed in order to understand the factors 
and/or pathway contributing a shift from some problematic symptoms of exercise to dependence. It should also be noted that amateur competitive exercisers had higher scores on the EDS and the number of individuals suffering from ED symptoms was also significantly higher in this group.

It was hypothesized that excessive exercise would have a positive impact on self-esteem and wellbeing due to improved outlook and performance (losing weight, more attractive body shape, better stamina, etc.). In contrast, it was found that both wellbeing and self-esteem showed lower values in case of higher ED scores. In the amateur competitive exerciser group there was an elevated risk of ED compared to the control group and a higher level of ED was associated with lower life satisfaction in this group. This relationship was not found in the recreational exerciser group. To summarize, more research is needed to settle the connection between ED and subjective well-being. It was hypothesized that participation in competitive sports would result in higher levels of subjective wellbeing due to the feeling of acknowledged efforts, However, the results of the present study provided no evidence to support such an assumption.

Although the study examined a novel group in the context of the exercise dependence field, there are clearly some limitations that need to be taken into account when interpreting the findings. The data were all self-report and subject to well known biases (including social desirability and memory recall). The number of individuals in the amateur competitive exerciser group was relatively small (compared to the relatively large number of individuals in the recreational exercise group) and the numbers of competitive exercisers that are classed as being at risk of ED was even smaller. This means that all the significant relationships between ED and other variables are based on a very small number of observations.

In summary, the present study highlights a number of significant factors related to exercise dependence, especially the connection between ED symptoms and lower self-esteem and lower levels of subjective wellbeing. These factors are worth considering when planning preventive interventions addressing ED for both amateur competitive exercisers and noncompetitive recreational athletes, while promoting sport as a healthy activity.

Acknowledgments This work was supported by the Hungarian Scientific Research Fund (grant numbers: K83884 and 111938).

\section{Compliance with Ethical Standards}

Author Disclosure Statement Zsuzsa Menczel, Mark D. Griffiths, István Vingender, Andrea Eisinger, Judit Farkas, Anna Magi, Barbara Mervó, Gyöngyi Kökönyei, and Zsolt Demetrovics declare that they do not have any interests which could constitute a real, potential or apparent conflict of interest with respect to his/her involvement in the publication. The authors also declare that they do not have any financial or other relations (e.g. directorship, consultancy or speaker fee) with companies, trade associations, unions or groups (including civic associations and public interest groups) that may gain or lose financially from the results or conclusions in the study. Sources of funding are acknowledged.

Ethical Issues All procedures followed were in accordance with the ethical standards of the responsible committee on human experimentation (institutional and national) and with the Helsinki Declaration of 1975, as revised in 2000. Informed consent was obtained from all subject for being included in the study.

\section{References}

Allegre, B., Therme, P., \& Griffiths, M. D. (2007). Individual factors and the context of physical activity in exercise dependence: a prospective study of 'ultra-marathoners'. International Journal of Mental Health and Addiction, 5, 233-243. 
Berczik, K., Szabó, A., Griffiths, M. D., Kurimay, T., Kun, B., Urbán, R., et al. (2012). Exercise addiction: symptoms, diagnosis, epidemiology, and etiology. Substance Use Misuse, 47(4), 404- 417.

Blaydon, M. J., \& Lindner, K. J. (2002). Eating disorders and exercise dependence is triathletes. Eating Disorders, 10(1), 49-60.

Costa, S., \& Oliva, P. (2012). Examining relationship between personality charasteristics and exercise dependence. Review of Psychology, 19(1), 5-12.

Gémes, K. (2006). Sport és életminőség. In.: Kopp, M., Kovács, M. (2006). A magyar népesség életminösége az ezredfordulón (pp. 167-180) Semmelweis Kiadó, Budapest.

Griffiths, M. D. (1997). Exercise addiction: a case study. Addiction Research, 5, 161-168.

Hausenblas, H. A., \& Symons Downs, D. (2002a). Relationship among sex, imagery, and exercise dependence symptoms. Psychology of Addictive Behaviors, 16(2), 169-172.

Hausenblas, H. A., \& Symons Downs, D. (2002b). Exercise dependence: a systematic review. Psychology of Sport and Exercise, 3, 89-123.

Hausenblas, H. A., \& Symons Downs, D. (2002c). Exercise dependence scale manual. University of Florida, Gainesville: Unpublished manuscript.

Lejoyeux, M., Avril, M., Richoux, C., Embouazza, H., \& Nivoli, F. (2008). Prevalence of exercise dependence and other behavioral addictions among clients of a Parisian fitness room. Comprehensive Psychiatry, 49(4), $353-358$

Lichtenstein, M. B., Larsen, K. S., Christiansen, E., Støving, R. K., \& Bredahl, T. V. G. (2014a). Exercise addiction in team sport and individual sport: prevalences and validation of the exercise addiction inventory. Addiction Research and Theory, 5, 431-437.

Lichtenstein, M. B., Christiansen, E., Bilenberg, N., \& Støving, R. K. (2014b). Validation of the exercise addiction inventory in a Danish sport context. Scandinavian Journal of Medicine and Science in Sports, $24,447-453$.

Modolo, V. B., Antunes, H. K., Gimenez, P. R., Santiago, M. L., Tufik, S., \& Mello, M. T. (2011). Negative addiction to exercise: are there differences between genders? Clinics (São Paulo, Brazil), 66(2), 255-260.

Mónok, K., Berczik, K., Urbán, R., Szabo, A., Griffiths, M. D., Farkas, J., et al. (2012). Psychometric properties and concurrent validity of two exercise addiction measures: a population wide study. Psychology of Sport and Exercise, 13(6), 739-746.

Morgan, J. F., Reid, F., \& Lacey, J. H. (1999). The SCOFF questionnaire: assesment of a new screening tool for eating disorders. British Medical Journal, 319, 1467-1468.

Rosenberg, M. (1965). Society and the adolescent self-image. NY: Princenton University Press.

Susánszky, É., Konkolÿ Thege, B., Stauder, A., Kopp, M. (2006). A WHO jól-lét kérdőív rövidített (WBI-5) magyar változatának validálása a Hungarostudy 2002 országos lakossági egészségfelmérés alapján. Metálhigiéné és Pszichoszomatika. 7(3), 247-255.

Szabo, A., \& Griffiths, M. D. (2007). Exercise addiction in British sport science students. International Journal of Mental Health and Addiction, 5, 25-28.

Szabo, A., Vega, R., Ruiz-Barquín, R., \& Rivera, O. (2013). Exercise addiction in Spanish athletes: investigation of the roles of gender, social context and level of involvement. Journal of Behavioral Addiction, 2, $249-252$.

Szabo, A., Griffiths, M. D., de La Vega Marcos, R., Mervo, B., \& Demetrovics, Z. (2015). Methodological and conceptual limitations in exercise addiction research. Yale Journal of Biology and Medicine, 86, 303-308.

Terry, A., Szabo, A., \& Griffiths, M. D. (2004). The Excercise addiction inventory: a new brief screening tool. Addiction Research and Theory, 12(5), 489-499.

Warburton, D. E., Nicol, C. W., \& Bredin, S. S. (2006). Health benefits of physical activity: the evidence. Canadian Medical Association Journal, 174(6), 801-809.

Warner, R., \& Griffiths, M. D. (2006). A qualitative thematic analysis of exercise addiction: an exploratory study. International Journal of Mental Health and Addiction, 4, 13-26.

Youngman, J. D. (2007). Risk for exercise addiction: a comparision os triathletes training for sprint-, olimpic-, half-ironman-, and ironman-distance trathlons. Open access dissertations. Paper 12. Retrieved: March 3, 2016 from: http://scholarlyrepository.miami.edu/cgi/viewcontent.cgi?article=1011\&context=oa dissertations 